\title{
ESCRIBIR DESDE LA TRINCHERA: MEMORIA Y COMPROMISO EN LA LITERATURA DE LA I GUERRA MUNDIAL ${ }^{1}$
}

\author{
JAVIER SÁNCHEZ ZAPATERO \\ Universidad de Salamanca
}

\section{El COMPROMISO INTELECTUAL}

El primer cuarto del siglo XX estuvo marcado por el conflicto bélico internacional que asoló Europa entre 1914 y 1918, bautizado primero como Gran Guerra y, después de los acontecimientos acaecidos entre 1939 y 1945, como I Guerra Mundial. La atención que produjo el acontecimiento fue inmensa, no sólo por la variedad de países e intereses a los que afectó, sino también por la ferocidad con la que se emplearon los bandos en lid, que, al hacer de la población civil potencial objetivo de sus acciones militares, produjo el doble de víctimas mortales que todos los conflictos bélicos registrados por la historia desde 1790 hasta 1914.

1 Recibido: 17/XI/2010 Aceptado: 8/I/2011 
En el debate social que trajo consigo la contienda se alzaron voces como la del alemán Ernest Jünger, la de la estadounidense Edith Warton o incluso la del español Vicente Blasco Ibáñez -quien, a pesar de la neutralidad de España en el conflicto, se mostró tremendamente crítico con el bando alemán en su exitosa novela Los cuatro jinetes del Apocalipsis, completada tras su visita al frente-, decididamente partidistas y deseosas de influir en los lectores mostrando visiones idealistas y demoníacas de los respectivos bandos en combate. Para la consecución exitosa de su objetivo de incidencia en los lectores utilizaron símbolos sugestivos con los que pretendían alterar y controlar opiniones, ideas, valores e incluso acciones: maniqueísmo moral, descripción de escenas de violencia y horror provocadas siempre por el bando contrario, sublimación de las virtudes, expresión de la legitimidad y la superioridad moral, inducción al odio, exaltación del nacionalismo y, en general, emociones, sentimientos y fantasías culturales estrechamente enlazadas con las ideas de amor al hogar y a la patria. Su papel, por lo tanto, fue el mismo que el de las maquinarias propagandísticas y mediáticas de los países a los que pertenecían.

Frente al interés particular de quienes abogaban por la victoria de uno de los bandos en combate, una serie de autores mantuvieron una defensa deideales universales como la hermandad entre los pueblos y el consiguiente rechazo a los conflictos basados en la defensa de intereses nacionales. La multiplicidad de sus orígenes y tradiciones culturales pone de manifiesto cómo los valores que asumieron trascendieron las barreras que la guerra estaba creando entre las diferentes nacionalidades. Fue tal la importancia en la esfera de pensamiento mundial en la época de lo que en ciertos sectores de la crítica se ha dado en llamar «autores pacifistas» que José Díaz Fernández llegó a tildar su producción de «nueva moral responsable del cambio de rumbo en los destinos en la sociedad humana ${ }^{2}$. Su capacidad de convertir la violencia bélica que recorría Europa en un sentimiento de fraternidad universal contrastaba con la actitud de los mensajes gubernamentales, que llamaban a las sociedades de los pueblos en liza al combate estimulando sus más bajas pasiones nacionalistas. Como expresó Stefan Zweig, con ello quedó demostrado la consolidación del modelo de autor autónomo, alejado de presiones particulares:

\begin{abstract}
Al fin y al cabo, uno era escritor, tenía la palabra y, por lo tanto, la obligación de expresar sus convicciones, aunque sólo fuese en la medida en el que le era posible. [...] El artista comprometido [estaba] obligado a expresar sus convicciones, aunque fuera luchando contra la oposición de su propio país e incluso contra la indignación de todo el mundo beligerante. [...] Era preciso luchar contra la guerra. ${ }^{3}$
\end{abstract}

\footnotetext{
${ }^{2}$ Francisco Caudet, Las cenizas del Fénix. La cultura española en los años 30, Madrid, Ediciones de la Torre, 1993, p. 410.

3 Stefan Zweig, El mundo de ayer. Memorias de un europeo, Barcelona, Acantilado, 2002, pp. 304 y 320. 
Es necesario distinguir entre aquellos intelectuales para los que la guerra supuso un factor de generación expresiva y aquellos otros para los que sencillamente fue un acontecimiento ante el que exponer una actitud social determinada. En el segundo grupo habría que adscribir, por ejemplo, a Romain Rolland o a Stefan Zweig, fervorosos defensores de la paz para los que la I Guerra Mundial no fue, sin embargo, tema ni estímulo literario. Al contrario que ellos, autores como Henri Barbusse o Erich M. Remarque estructuraron con sus obras de tema bélico -respectivamente, El fuego. Diario de un pelotón y Sin novedad en el frente- un discurso literario responsable y consciente de sus implicaciones éticas para establecer esa postura de combate reclamada por Zweig en la anterior cita. Excombatientes en ambos casos, concibieron la literatura como una función social y ejemplarizante a través de la que mostrar su rechazo a la contienda. Según Fulgencio Castañar, «su carácter social no les hace rechazar la categoría intrínseca que se encierra en una obra de arte, pero posponen lo estético a lo social, el arte al hombre $»^{4}$. Sus discursos trascienden su calidad literaria para ser condicionados por la experiencia vital y la postura moral que los condiciona, como explicó Jean Paul Sartre:

A los lectores, acosados sin tregua por una preocupación única, sólo podía convenirles un tema: teníamos que escribir de su guerra, de su muerte. Reintegrados bruscamente a la historia, estábamos constreñidos a hacer una literatura de historicidad. ${ }^{5}$

\section{Testimonios DE GUERRA}

La participación en la batalla se convirtió en el generador expresivo necesario para que los autores convirtieran su obra literaria en vehículo a través del que luchar contra la guerra. Estimulados por el imperativo moral que hacía concebir la suya como una experiencia de dimensiones universales capaz de extenderse en el tiempo, los autores participantes en combate dejaron testimonio escrito de lo vivido por ellos, convirtiendo así sus recuerdos en memoria ejemplar capaz de adquirir funcionalidad. De ahí que, por ejemplo, Erich M. Remarque señalase en el prólogo de Sin novedad en el frente que su novela pretendía «únicamente mostrar una generación que fue destruida por la guerra, aunque escapara a las granadas $\gg^{6}$, poniendo así implícitamente de manifiesto su deseo de que en el futuro situaciones semejantes no se repitiesen. Del mismo modo, el escritor estadounidense John Dos Passos -que participó en la guerra como voluntario conduciendo ambulancias- mostró durante la contienda su intención

\footnotetext{
${ }^{4}$ Fulgencio Castañar, El compromiso en la novela de la II República Española, Madrid, Siglo XXI, 1992, p. 33.

5 Jean Paul-Sartre, ¿Qué es la literatura?, Barcelona, Losada, 2003, p. 243.

6 Erich M. Remarque, Sin novedad en el frente, Barcelona, Edhasa, 2005, p. 7.
} 
de «encontrar algún medio de responder a la propaganda de guerra con propaganda de $p a z »^{7}$.

Henri Barbusse, por su parte, explicó en una carta enviada al novelista Vicente Blasco Ibáñez las razones de su participación en el conflicto:

Me enganchévoluntariamente en la Infantería a consecuencia de mis ideas antimilitaristas. Tuve la convicción de que debía hacer esta vez la guerra a la guerra, morir si era preciso, para que en lo futuro no surjan más guerras. ${ }^{9}$

Semejante declaración de principios e intenciones no hace sino poner de manifiesto la voluntad con la que el escritor francés abordó la escritura de la novela basada en sus experiencias en el frente de batalla, publicada por entregas a partir del año 1916. Mientras permaneció en las trincheras, Barbusse fue anotando minuciosamente todo cuanto acontecía a su alrededor. Comenzó a redactar su novela meses después de su estancia en el frente, durante la temporada que hubo de convalecer en el hospital aquejado de diversas enfermedades contraídas por las penosas condiciones de salubridad que hubo de sufrir durante su periplo militar, y en todo momento fue consciente de dotar a su texto de la misma finalidad ética de su decisión de alistarse.

También Dos Passos escribía a diario lo que el contexto bélico le sugería, asumiendo el valor terapéutico que la escritura puede adoptar en las circunstancias de tensión:

Yo solía tenderme en una de las literas del refugio subterráneo y llenar mi bloc de notas con la retórica típica de los veintiún años. [...] Analizar las sensaciones de peligro y de miedo era mi manera de hacerlas tolerables. ${ }^{10}$

Remarque combatió en el ejército alemán, mientras que Barbusse lo hizo en el francés. No fueron, sin embargo, los únicos escritores que hicieron de su experiencia bélica material literario, como evidencian los casos del ya citado Dos Passos y de sus compatriotas Ernest Hemingway, E. E. Cummingsy William Faulkner-que participaron en la guerra como voluntarios de las secciones sanitarias que acompañaban a los soldados norteamericanos en los dos primeros casos y como miembro de la fuerza aérea en el tercero- o de los alemanes Ernest Glaeser y Arnold Zweig. Soldados, voluntarios o incluso miembros de la sociedad civil convertidos en meras víctimas del conflicto -

\footnotetext{
7 John Dos Passos, Años inolvidables, Seix Barral, Barcelona, 2006, p. 86.

8 Barbusse había sido declarado inútil para el servicio militar por sufrir pleuritis y se alistó en el ejército de forma voluntaria.

9 Vicente Blasco Ibáñez, Obras completas, Madrid, Aguilar, 1965, p. 1615.

10 John Dos Passos, op. cit., p. 90.
} 
como Glaeser, cuya niñez se vio truncada por la virulencia de la guerra- trascendieron su personal periplo existencial para transformarlo en un discurso antibelicista de dimensiones universales, capaz de activarse en el presente y obviar la concreción de sus dimensiones espaciales y temporales. De hecho, a los autores les interesaba recalcar la veracidad de lo narrado en sus obras y dejar claro que lo que aparece en ellas era fruto de sus propios recuerdos o de la labor documental. Su objetivo, pues, no era otro que ser capaces «de expresar [...] toda la tragedia y la horrible emoción que la acompaña» ${ }^{11}$. Paradigmático ejemplo de esta obsesión por recrear de manera fidedigna lo que ocurría en las trincheras es el pasaje de El fuego. Diario de un pelotón en el que varios soldados preguntan al personaje trasunto de Barbusse, un miembro del batallón que ha expresado su voluntad de escribir sobre su participación en el conflicto, si va a utilizar palabras malsonantes y blasfemias en su relato de los hechos ${ }^{12}$. Más allá de la anécdota -que, por otro lado, revela el siempre latente problema de la representación de las situaciones caracterizadas por su elevado nivel de intensidad emocional, al señalar varios de los personajes participantes en el diálogo que sin la utilización de esas expresiones es imposible dar cuenta de la vivencia bélica-, el fragmento evidencia la importancia, que parece lindar con la necesidad, de mantener fidelidad entre lo narrado y lo experimentado. También Louis-Ferdinand Céline, que luchó en las filas del ejército francés, expresó en su novela autobiográfica Viaje al fin de la noche la fuerza e intensidad de sus vivencias en el frente a través de la utilización de un léxico obsceno e irreverente. Para representar los horrores de la guerra, el autor francés recurrió al uso constante de puntos suspensivos, con los que parecía querer expresar la inefabilidad del fenómeno.

Esa insistencia subraya el carácter híbrido, a medio camino entre la novela y la autobiografía, de sus textos sobre la I Guerra Mundial, pues plantea la paradoja de por qué insistir en la confrontación de lo relatado con la realidad si por el pacto narrativo el lector renuncia a las pruebas de verificación y el autor al principio de sinceridad. Cabe preguntarse, por tanto, por qué el criterio de referencialidad resulta de tanta importancia para estos escritores.

La respuesta a esa interrogación parece ser doble. En primer lugar, a quienes conocieron de primera mano el horror de la I Guerra Mundial -sobre todo a aquellos que lucharon en el frente franco-alemán- les interesa que sus lectores conozcan la realidad de lo que estaba ocurriendo en las trincheras. Frente a la propaganda vertida desde los medios de comunicación, convertidos en vehículos de información oficial a través de los que esconder al pueblo la verdadera situación de los ejércitos -ocultando

\footnotetext{
11 Ibid., p. 90.

12 Henri Barbusse, El fuego. Diario de un pelotón, Madrid, Caro Baroja, 1927, pp. 171-172.
} 
las bajas y las derrotas de los nacionales y exagerando desmesuradamente las de los extranjeros-, sus libros se convierten en testimonio histórico susceptible de ser asumido como interpretación de los acontecimientos. Su literatura se transforma así en una forma de transmitir al pueblo la verdad de lo sucedido. $\mathrm{O}$, al menos, la verdad de lo sucedido en el limitado ámbito de percepción de quienes lucharon en la guerra. En la literatura bélica de la I Guerra Mundial no existen explicaciones globales del conflicto, ni visiones cenitales que permitan dar sentido a todos los acontecimientos. Llegando a dudar de que éstas existan, lo que los autores se limitan a mostrar es la cruda realidad por ellos vivida. Frente a las informaciones de los periódicos y a sus continuas referencias a victorias, avances militares y castigos al enemigo, las obras de quienes participaron en el conflicto se limitan a mostrar la cotidianeidad de la guerra, llena de barro, sangre y metralla.

En segundo lugar, la importancia de la veracidad de lo narrado reside en la autoridad de la que parece revestirse su pacifismo. Haber sido víctimas del conflicto y, por tanto, conocedores de toda su dimensión destructora, dota a su postura contraria a la guerra de un carácter novedoso que la distingue de toda la tradición antibelicista e internacionalista a la que se adscribe -y de la que habría antecedentes en la historia de la literatura desde prácticamente sus orígenes, como pone de manifiesto el caso de Aristófanes-, al tiempo que demuestra que su compromiso no era sino la mera expresión de su vivencia.

Concebidas como vehículos a través de las que relatar sus experiencias en la I Guerra Mundial, las obras compuestas por los testigos y víctimas de la guerra se sitúan a medio camino entre el estatuto narrativo y el autobiográfico. Sin novedad en el frente -Erich M. Remarque-, Los que teníamos doce años -Ernest Glaeser-, El sargento Grischa -Arnold Zweig-, El fuego. Diario de un pelotón -Henri Barbusse-, Cuatro de infantería: últimos dias en el frente occidental en 1918 -Ernest Johanssen-, Tres soldados -John Dos Passos-, La habitación enorme -E.E. Cummings-, La paga de los soldados -William Faulkner-, Adiós a las armas -Ernest Hemingway- y algunos fragmentos de Viaje al fin de la noche -Louis-Ferdinand Céline- y de Adiós a todo eso -Robert Graves- son los textos en los que se basan las conclusiones del análisis de este artículo. A pesar de sus diferencias, comparten el mantenimiento de una postura crítica contra la guerra y los intereses que llevaron a ella. Además, todas ellas muestran de qué forma los seres humanos se ven afectados por su participación en la guerra. Al tratarse de un corpus no limitado ni nacional ni culturalmente, queda evidenciado el carácter universal de su mensaje pacifista y de su interpretación de la guerra como fenómeno destructor.

A pesar de que las obras fueron editadas en colecciones de novelas, y presentadas como tal al público, los autores admiten en ellas haber sido sinceros y no contar más 
que los recuerdos y las sensaciones vividas en el frente -de hecho, se refieren a hechos sucedidos e incluso susceptibles de ser verificados-. Su lectura sugeriría, pues, un pacto ambiguo, reforzado en ocasiones -aunque en todos los casos; sí, por ejemplo, en Los que teníamos doce años, pero no en Tres soldados- por una explícita identificación -incluso nominal- entre el autor, el personaje y el narrador.

$\mathrm{Al}$ estar generadas por recuerdos individuales, lo que transmiten estas novelas es la versión de la guerra de los autores. Las pequeñas tragedias que esconde un acontecimiento tan monstruoso como la guerra, habitualmente silenciadas y omitidas de los imaginarios sociales, van a ocupar el primer plano de sus narraciones, que van a dotarse así de lo que algunos autores han denominado «carácter democrático» ${ }^{13}$. $\mathrm{Al}$ dar recursos lingüísticos a los marginados de la historia -los soldados que sufren en las trincheras, los muertos que caen en combate, los habitantes de las ciudades bombardeadas acostumbrados a vivir con el miedo...- para que su discurso pueda hacerse oír, estas obras ayudan a la creación de una esfera pública carente de verdades únicas.

Junto a su propia experiencia, los autores disponen de una tradición de literatura bélica para vertebrar sus relatos. Si por un lado se va a prescindir de los modelos clásicos centrados en el valor y en el heroísmo, por otro se van a tomar como referente novelas como La cartuja de Parma -Stendhal-, Guerra y paz -Lev Tosltoi- o La roja insignia del valor -Stephen Crane-, caracterizadas por presentar en el frente a personajes jóvenes e idealistas, tan deseosos de conocer la épica de la batalla como decepcionados por no encontrar en ella nada más que caos, destrucción y muerte. Así, es sintomático que, por ejemplo, el protagonismo de las novelas pacifistas suela otorgarse a personajes jóvenes que, además de mantener similares características a las de los autores en el momento de experimentar los hechos por ellos narrados, presentan ciertas concomitancias con los modelos antiheroicos típicos de la tradición iniciada por Stendhal. No hay, sin embargo, en los personajes prototípicos de la literatura bélica del siglo XX rastro alguno de idealismo. Al contrario, son presentados como seres inertes que desconocen las razones que les han llevado hasta el frente $y$, con ello, a verse abocados a un horizonte de destrucción, violencia y muerte. Aplicando la teoría sobre la tipología de personajes y su utilización desarrollada por Northrop Frye, podría concluirse que en este tipo de obras se utiliza el mito del guerrero desde un «prisma irónico» ${ }^{14}$. La conversión del tradicional héroe en un personaje profundamente antiheroico no hace sino poner de manifiesto la decadencia de una sociedad en trances de destrucción por la perversión

${ }^{13}$ Txetxu Aguado, «Imán, La ruta y El blocao: memoria e historia del desastre de Annual», Revista hispánica moderna, 57 (2004), p. 114.

${ }^{14}$ Northrop Frye, Anatomía de la crítica, Caracas, Monteávila, 1957, pp. 35-50. 
de las clases dominantes. En la literatura de la I Guerra Mundial, es frecuente que esa desorientación se acompañe de una crítica a las generaciones anteriores, responsables del conflicto:

Deberían haber sido para nosotros, jóvenes de dieciocho años, mediadores y guías que nos condujeran a la vida adulta, al mundo del trabajo, del deber, de la cultura y del progreso, hacia el porvenir. A veces nos burlábamos de ellos y les jugábamos alguna trastada, pero en el fondo teníamos fe en ellos. La misma noción de la autoridad que representaban les otorgaba a nuestros ojos mucha más perspicacia y sentido común. Pero el primero de nosotros que murió echó por los suelos esa convicción. Tuvimos que reconocer que nuestra generación era mucho más leal que la suya; no tenían más ventajas respecto a nosotros que las palabras vanas y la habilidad. El primer bombardeo nos reveló nuestro error, y con él se derrumbó la visión del mundo que nos habían enseñado.

Mientas ellos seguían escribiendo y discurseando, nosotros veíamos ambulancias y moribundos; mientras ellos proclamaban como sublime el servicio al Estado, nosotros sabíamos ya que el miedo a la muerte es mucho más intenso. Por eso no nos convertimos en rebeldes, ni en desertores ni en cobardes -ello se servían de esas expresiones con gran facilidad-; amábamos a nuestra patria tanto como ellos, y nos aprestábamos al combate con coraje; pero ahora teníamos capacidad de discernimiento, de improviso habíamos aprendido a ver y vimos que no quedaba ni rastro de su mundo. ${ }^{15}$

Esta crítica, evidente también en novelas como Tres soldados o El fuego. Diario de un pelotón -en la que se llega a comparar a los soldados con «esclavos» y con «pobres muñecos engañados y embrutecidos animales domésticos» ${ }^{16}$ al servicio de unos intereses- entronca las novelas de la I Guerra Mundial con la «literatura de crisis» de principios de siglo, en la que se ponía de manifiesto el fin de las actitudes existenciales decimonónicas y se abogaba por un nuevo modelo social y cultural que destronase al

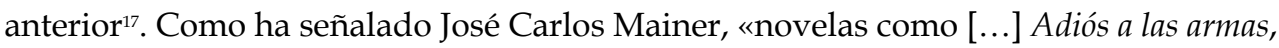
de Ernest Hemingway, Tres soldados de John Dos Passos [...] pueden dar, entre otras muchas, la tónica de desencanto, nostalgia y desamparo de una juventud ${ }^{18}$.

\section{UNIVERSALISMO ANTIBELICISTA}

Mostrar a los combatientes como individuos alejados de los intereses por los que se estaba peleando en el campo de batalla permite vertebrar un discurso antibelicista basado en la artificiosidad de la guerra, que conduce hasta la lucha a muerte a jóvenes

\footnotetext{
${ }^{15}$ Erich M. Remarque, op. cit., p. 19.

16 Henri Barbusse, op. cit., p. 345.

17 El título de la obra Robert Graves Adiós a todo eso ejemplifica gráficamente la ruptura generacional que muestran estas obras.

18 José Carlos Mainer, La Edad de Plata (1902-1929), Madrid, Crítica, 1975, p. 173.
} 
incapaces de entender el odio que han de sentir hacia su adversario. La penetración de las ideas internacionalistas en el cuerpo intelectual del primer tercio del siglo XX ayudó a desarrollar esta posición antibelicista, basada en la hermandad de los seres humanos por encima de cualquier tipo de división cultural artificial -en el caso de la guerra, la pertenencia a una determinada patria-. De ahí que en la novela testimonial de Henri Barbusse se pueda leer que «dos ejércitos que combaten son un ejército que se suicida» y se insista constantemente en la igualdad de los soldados de ambos bandos:

¡Pobres semejantes, pobres desconocidos, a vosotros os toca ahora el turno! Otra vez seremos nosotros. Mañana, tal vez, veremos el cielo estallar sobre nuestras cabezas, o la tierra abrirse a nuestros pies. ${ }^{19}$

En Sin novedad en el frente apenas hay referencias sobre la identidad de los bandos en combate y la primera referencia nacionalista - «reconocemos los rostros crispados, los cascos planos: son franceses $»^{20}$ - no aparece hasta el capítulo sexto de los doce de que consta la novela. Su autor describe con minuciosidad y realismo el horror del combate, la tensa angustia de la retaguardia y las precarias condiciones en las que permanecen los soldados sin referencias localistas, lo que permite trascender su visión a todas las guerras y a todos los frentes. Se hace hincapié continuamente en estas y otras novelas de similar temática y estructura en lo indiferente que la guerra -vista como un asunto de «alta política»- resulta para los combatientes, muchas veces obreros más cercanos a la sensibilidad e intereses de los soldados del bando contrario que a sus propios cabecillas. Por eso se insiste continuamente en la descripción de aspectos materiales como los uniformes para ejemplificar que, sin ellos, no hay diferencias entre los soldados o se identifica la guerra exclusivamente con intereses que en nada afectan a los combatientes:

Ahora quiere saber cómo empieza una guerra.

- Generalmente porque un país ofende a otro. [...]

- ¿Un país? No lo entiendo. Una montaña alemana no puede ofender a una montaña francesa. Ni un río, ni un bosque, ni un campo de trigo... [...]

- Se refiere al pueblo en conjunto, es decir, al Estado. [...]

- El Estado, el Estado... Guardia rural, policía impuestos... eso es vuestro Estado.

Si vosotros tenéis algo que ver con todo eso, yo no. [...]

- Tienes razón. Entre el Estado y la patria hay algunas diferencias [...]

- Pero se corresponden mutuamente. No existe una patria sin Estado.

19 Henri Barbusse, op. cit., pp. 11 y 222.

20 Erich M. Remarque, op. cit., p. 107. 
- De acuerdo, pero piensa que la mayoría de nosotros somos gente [alemana] sencilla. Y también en Francia la mayoría son obreros, artesanos o pequeños empleados. ¿Cómo puede querer atacarnos un zapatero o un cerrajero francés? No, son únicamente los gobiernos. Antes de venir aquí, yo no había visto nunca a un francés, y a la mayoría de franceses les debe suceder lo mismo con nosotros. A ellos tampoco les han pedido su opinión. ${ }^{21}$

Louis-Ferdinand Céline ridiculizó en Viaje al fin de la noche los sentimientos de patriotismo a través de la reducción de las diferencias entre las diversas naciones a una aleatoria secuencia numérica:

Vamos a ir al encuentro de esos malnacidos que han invadido la patria $\mathrm{n}^{\circ} 2$, y les vamos a saltar los sesos. ¡Adelante! ¡Adelante! ¡A bordo hay cuanto hace falta! [...] ¡Viva la patria $n^{\mathrm{o}} 1$ !. ${ }^{22}$

De forma análoga, subrayó el absurdo de la guerra al presentarla como un espacio irracional por el que el hombre deambula desconcertado, sin poder entender la violencia arbitraria que le rodea. Su narrador y protagonista -cuya identificación referencial con Céline es prácticamente absoluta, aunque no exista entre autor y personaje correspondencia nominal- revela este carácter incoherente al exhibir su perplejidad, basada en la subversión de la lógica de la relación causa / efecto ante los acontecimientos presenciados en el campo de batalla:

Había [...] dos alemanes que llevaban más de un cuarto de hora disparando. [...] Nuestro coronel tal vez supiera por qué disparaban aquellos dos; quizá los alemanes lo supiesen también, pero yo, la verdad, no. Por más que me refrescaba la memoria, no recordaba haberles hecho nada a los alemanes. Siempre había sido muy amable y educado con ellos. [...] No había quien entendiera la guerra. ${ }^{23}$

Entender la crítica que subyace al pasaje de Viaje al fin de la noche de la cita anterior sólo es posible si se tienen en cuenta, por un lado, la influencia del universalismo como eje de la teoría pacifista, y, por otro, la actitud vitalista que diferencia a los autores críticos con la guerra de los intelectuales que, como Ernest Jünger, la concebían como principio supremo de la vida y la cultura. Evidentemente, si se entiende la guerra como un acto valeroso por el que merece la pena incluso morir, no hay lugar para el rechazo ni el cuestionamiento.

El sentimiento internacionalista aparece reflejado en Adiós a las armas a través de su eje argumental: la relación sentimental de dos personajes de diferente origen ${ }^{24}$ en el

\footnotetext{
$21 \quad$ Ibid., pp. 185-186.

${ }^{22}$ Louis-Ferdinand Céline, Viaje al fin de la noche, Barcelona, Edhasa, 2007, p. 16.

23 Ibid., p. 18-19.

${ }^{24}$ El personaje principal masculino es un teniente del ejército italiano de nacionalidad estadounidense,
} 
marco de la campaña italiana de la guerra. De forma similar, Ernest Glaeser expresó su convicción en la hermandad de todas las nacionalidades en su novela autobiográfica Los que teníamos doce años mostrando la amistad entre dos niños, uno francés y otro germano. Además de exponer de forma gráfica el choque generacional que supuso la guerra -«¿qué me importaba a mí la guerra?, ¿qué me importaba a mí el mundo de los mayores? $\gg^{25}$, clama el narrador en un momento del texto-, la obra muestra el impacto que sobre la población civil tuvo la I Guerra Mundial. Ambientada en la zona de la retaguardia, Los que teníamos doce años pone de relieve el envilecimiento que sufrió la sociedad europea, obcecada en crear barreras y diferencias entre sus diferentes miembros ${ }^{26}$, frente a la sana amistad que parece unir a los dos personajes protagonistas:

\begin{abstract}
Absorto en mi amistad con Gastón, no había advertido apenas cómo había cambiado el ambiente social en el hotel. Ya no reinaba aquella mezcolanza pintoresca en que se confundían los súbditos de diferentes naciones. [...] Los huéspedes empezaban a clasificarse según los colores de la bandera de su país. Los ingleses no querían nada con los alemanes [...]; los franceses se desviaban de los austriacos. [...] Todo el mundo se clasificaba e iba a ocupar la casilla que le correspondía, obedeciendo leyes misteriosas. ${ }^{27}$
\end{abstract}

Una de las palabras que con más frecuencia se ha utilizado en la tradición de la literatura bélica es «herida». Gracias a su polisemia -entre sus acepciones recogidas por el DRAE figuran las de «perforación o desgarramiento en algún lugar de un cuerpo vivo», «golpe de las armas blancas al herir con ellas» y «aquello que aflige y atormenta el ánimo»-, el término ha sido empleado para expresar los daños físicos y el trauma psíquico provocados por la guerra. Junto a ese uso literal, ha existido otro de carácter metafórico con el que se pretendía expresar el brutal impacto derivado de la contemplación -y, en ocasiones, la responsabilidad en la creación- de los horrores

mientras que la protagonista femenina es escocesa. Su relación está basada en el romance que el propio Hemingway vivió con una enfermera en un hospital de campaña -al que acudió herido en las piernas, como el protagonista de la novela-.

25 Ernest Glaeser, Los que teníamos doce años, Madrid, Cenit, 1929, p. 154.

26 Stefan Zweig reflexionó también sobre la creciente importancia de las fronteras debido a la tensión internacional generada por la I Guerra Mundial en su libro El mundo de ayer. Memorias de un europeo: «Tal vez nada demuestra de modo más palpable la terrible caída que sufrió el mundo a partir de la Primera Guerra Mundial como la limitación de la libertad de movimientos del hombre y la reducción de su derecho a la libertad. Antes de 1914 la Tierra era de todos. Todo el mundo iba donde quería y permanecía allí el tiempo que quería. No existían permisos ni autorizaciones, me divierte la sorpresa de los jóvenes cada vez que les cuento que antes de 1914 viajé a la India y América sin pasaporte y que en realidad jamás en mi vida había visto uno. La gente subía y bajaba de los trenes sin preguntar ni ser preguntada, no tenía que rellenar ni uno del centenar de papeles que se exigen hoy en día. No existían salvoconductos ni visados ni ninguno de estos fastidios; las mismas fronteras que hoy aduaneros, policías y gendarmes han convertido en una alambrada, a causa de la desconfianza patológica de todos hacia todos, no representaban más que líneas simbólicas que se cruzaban con la misma despreocupación que el meridiano de Greenwich» (Stefan Zweig, op. cit., p. 154).

27 Ernest Glaeser, op. cit., p. 153. 
bélicos. Quien es testigo de semejantes niveles de brutalidad y dramatismo queda marcado para el resto de su vida, como si hubiera sufrido una herida que hubiera cicatrizado en su piel haciéndose así imposible de olvidar.

El símbolo de la herida resulta de suma utilidad para comprender de qué modo presenta la guerra Ernest Glaeser. Aludiendo a su periplo vital, muestra que fue un fenómeno que determinó el devenir de varias generaciones de europeos, dejando grabada una huella indeleble en la evolución personal de todos ellos. Del mismo modo que como suceso social la I Guerra Mundial fue interpretada como un acontecimiento simbólico y crucial -lo que provocó que tras su resolución el desarrollo histórico quedara dividido en dos periodos delimitados por ella- como experiencia personal supuso un elemento traumático de tal fuerza que la hizo ser considerada una especie de «rito de iniciación» susceptible de modificar radicalmente la personalidad. En Los que teníamos doce años, esa interpretación cobra especial sentido gracias a la ligera vinculación que la obra mantiene con las novelas de formación. Si en éstas se narraba el proceso de desarrollo hasta la edad adulta de un personaje, en la novela de Glaeser se relataba el paso de la infancia a la madurez que sufre el niño protagonista. Lejos de ser una evolución pautada y convencional, es el suyo un rápido crecimiento en el que conceptos propios de la niñez como la inocencia o la confianza en el ser humano adulto se desmoronan con la misma velocidad con la que se ha de acostumbrar a relacionarse con experiencias como la muerte o la violencia física. Oscilante entre la incomprensión inicial y la brutalidad final -la obra concluye con la muerte en un bombardeo de la novia del protagonista, que se da cuenta así de forma abrupta y terrible de las dimensiones dramáticas del conflicto-, la novela muestra a través del subjetivo prisma de un narrador infantil, y, por tanto, no fiable, como la guerra trastoca y pervierte todo. Al principio de la obra, el protagonista ve la contienda como algo indiferente para él y absolutamente alejado de sus preocupaciones. Es, sencillamente, uno más de los aburridos temas sobre los que conversan las personas mayores. A medida que la trama va avanzando, los efectos de la guerra comienzan a notarse en la retaguardia -falta de provisiones, enfrentamientos sociales, ataques aéreos, etc.- y los personajes han de acostumbrarse a convivir con la destrucción y con la muerte, lo que modifica su personalidad y comportamiento. Así, el autor muestra -además de la extensión de los frentes de batalla a prácticamente todos los lugares de los países en lid-, el trágico fin de la juventud de toda una generación. No en vano, Mainer ha asegurado que toda literatura de guerra «adopta el tono de una confesión centrada en la conversión»y, por tanto, «es la [confesión] de una juventud inmolada y es también la inmolación» ${ }^{28}$.

\footnotetext{
28 José Carlos Mainer, «Agustín de Foxá: Madrid, de corte a cheka», en Agustín Sánchez Vidal (coord.), Época contemporánea (1914-1939). Primer suplemento. Volumen de Historia y Crítica de literatura española, dirigida por Francisco Rico, Barcelona, Crítica, 1995, pp. 574-577.
} 
También el narrador homodiegético de Sin novedad en el frente manifiesta en una de sus reflexiones las consecuencias que para el proceso de desarrollo de los soldados ha tenido la vida militar y la cotidiana convivencia con el horror:

Hoy pasaríamos por el paisaje de nuestra juventud como viajeros. Los hechos nos han consumido, conocemos las diferencias como comerciantes y las necesidades como carniceros. Ya no somos despreocupados, somos terrible indiferentes. Estaríamos allí, pero ¿viviríamos? Estamos abandonados como niños y somos experimentados como ancianos. Somos groseros, tristes, superficiales... Creo que estamos perdidos. ${ }^{29}$

Hay un pasaje de la novela de Remarque que muestra de modo ejemplar la transformación personal que llevan aparejados los conflictos bélicos. El protagonista regresa a su casa aprovechando un permiso otorgado por los superiores de su batallón y, mientras observa la que durante años fue su habitación en la casa familiar, descubre que prácticamente nada queda en él de aquel que fue antes de partir al frente. La guerra le ha convertido en un ser diferente, capacitado para observar su pasado como si fuera algo completamente ajeno a él:

Quiero sentir que pertenezco a esta casa, quiero escuchar su voz para saber, cuando vuelva al frente, que la dulce ola del regreso ahoga la guerra; ya ha quedado atrás, ya no nos carcome, no tiene más poder sobre nosotros que el puramente externo [...] De pronto surge ante mí un terrible sentimiento de extrañeza. No puedo encontrar el pasado. Me rechaza. Es inútil que implore y me esfuerce. Nada vibra. Indiferente y triste, estoy aquí sentado como un réprobo mientras el pasado me da la espalda. ${ }^{30}$

Existe en toda la literatura antibelicista la consideración del conflicto como un acontecimiento determinante para la vida de los individuos ${ }^{31}-0$, según lo expuesto, una herida imposible de cicatrizar-. Así, el narrador de Viaje al fin de la noche señala tras su primera toma de contacto con el ambiente de muerte y barbarie de la guerra que «había quedado desvirgado» ${ }^{32}$. La imposibilidad de olvidar lo vivido fue expresada en Sin novedad en el frente en un diálogo en el que varios personajes imaginan cómo será su vida cuando regresen al hogar y dejen el frente. Mientras que uno de los personajes señala lo problemático que resultará para todos ellos adaptarse a la vida cotidiana

\footnotetext{
29 Erich M. Remarque, op. cit., p. 116.

30 Ibid., p. 159.

31 El propio Erich M. Remarque narró en su novela El retorno la imposibilidad de los excombatientes de adaptarse sin problemas a la vida convencional después de 1918. Tras la guerra, todo y todos habían cambiado. Su protagonista, un maestro que combatió en las trincheras, muestra cómo toda su existencia ha quedado marcada por la guerra, invalidándola para siempre, algo que se explica sintomáticamente en la falta de confianza que tiene en la labor docente que implica su trabajo. ¿Para qué educar a los niños -parece preguntarse- si la guerra va a convertirles en seres irracionales ávidos de violencia?
}

${ }^{32}$ Louis-Ferdinand Céline, op. cit., p. 22. 
después de la guerra, otro afirma que «dos años de disparos y bombas de mano» no pueden borrarse ni «quitarse de encima como unos calcetines» ${ }^{33}$. No en vano, el anhelo del pasado, habitualmente presentado como un tiempo plácido completamente diferente al opresivo espacio bélico, es una de las constantes de este tipo de novelas. Recrear el pasado permite a los autores regresar a una etapa de su vida virginal e inocente, no marcada aún por el trauma de la guerra.

En la novela testimonial de Barbusse, el carácter indeleble de la huella dejada por la experiencia bélica es reflejado por el narrador al afirmar que su trabajo cuando todos los enfrentamientos hayan terminado será «borrar este presente, y borrarlo más de lo que se piensa, como si fuera algo abominable y vergonzoso» ${ }^{34}$. En este sentido, la vinculación de la guerra con otros acontecimientos marcados por la violencia y el dramatismo como el exilio o la estancia en un campo de concentración es absoluta. Todas son experiencias traumáticas imposibles de ser olvidadas por quien las sufre, lo que incide en la necesidad de producir un testimonio que permita asimilarlas y otorgarlas cierto sentido.

\section{Crítica de la deshumanización}

En general, en prácticamente todas las novelas estudiadas en este artículo se insiste en cómo la violencia generalizada, la intensidad de las batallas y la tensión de la vida en las trincheras -y en las zonas de la retaguardia amenazadas por los bombardeos- provocan la conversión de los hombres en maquinarías de destrucción:

Nos hemos convertido en animales peligrosos. No luchamos, nos defendemos contra la destrucción. No lanzamos las granadas contra los hombres, qué sabemos nosotros de eso en ese instante, la muerte nos acosa con manos y cascos, por primera vez en tres días podemos mirarla a la cara; por primera vez en tres días podemos defendernos de ella, nos posee una furia inmensa; ya no tenemos que esperar, impotentes, sobre el patíbulo; podemos destruir y matar para salvarnos [...] Si tu propio padre viniera con los de enfrente, no dudarías en lanzarle una granada al pecho. ${ }^{35}$

La degradación a la que se ve sometido el ser humano se intensifica con la pérdida de individualidad que producen la vida militar y el contexto bélico, pues «un soldado [...] no es nada en la multitud, se encuentra como perdido, ahogado en unas

33 Erich M. Remarque, op. cit., p. 85.

${ }^{34}$ Henri Barbusse, op. cit., p. 528. Lejos de lo que en un principio pudiera pensarse, la afirmación del narrador de El fuego. Diario de un pelotón no aboga por un mero olvido de lo sucedido. Al contrario, parece optar por un recuerdo constante que se convierta en «antídoto contra la guerra» (Ibid., p. 332). Borrar lo sucedido no implica no acordarse de ello, sino que no vuelva a repetirse en la historia.

35 Erich M. Remarque, op. cit., p. 108. 
gotas de sangre [...] en medio de un diluvio de hombres y cosas» ${ }^{36}$. Así, el proceso de deshumanización no hace sino denunciar el carácter inhumano de la guerra, capaz de modificar a todo aquel que se ve inmerso en ella. Además de por las lógicas consecuencias que se derivan de experimentar sensaciones de extrema intensidad como las provocadas por la guerra, la transformación viene generada por las características contextuales de los escenarios bélicos. Vivir en unas condiciones infrahumanas, más propias de animales que de personas, y en constante convivencia con la muerte, resulta degradante, como evidencia Henri Barbusse cuando recuerda en su novela testimonial cómo en determinadas ocasiones los soldados se veían obligados a dormir junto a los

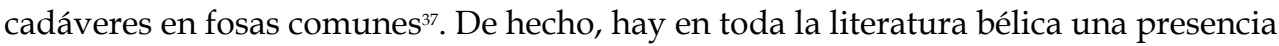
continua y obsesiva de la muerte, manifestada tanto a nivel formal -a través del léxico utilizado- como a nivel temático -a través de las reflexiones y comportamientos ante ella de los personajes-:

A mis pies yacía la gorra de un soldado, mezclada con sus sesos. Nunca había visto un cerebro humano. De alguna manera lo había asociado siempre con un concepto poético. Uno puede bromear con un soldado malherido y felicitarlo porque lo han puesto fuera de combate. Se puede no hacer caso de un cadáver. Pero [...] [no se puede] bromear con un hombre que tarda tres horas en morir después de que le hayan volado la parte superior de la cabeza con un proyectil disparado a veinte metros de distancia. ${ }^{38}$

El proceso de deshumanización es expuesto en las novelas de guerra a través de varios procedimientos. Uno de ellos es el de la continua comparación de los soldados con animales y bestias por la progresiva limitación de sus preocupaciones a la satisfacción de sus necesidades primeras -«al soldado, su estómago y su digestión le resultan terreno más familiar que a cualquier otra persona» ${ }^{39}$ - y por la brutal gratuidad con la que emplea la violencia. «Osos que patalean y gruñen ${ }^{40}$, seres que «emiten ronquidos mezclados con ruidos animales» ${ }^{41} \mathrm{y}$ «comen pienso» ${ }^{42}$, «animales

\footnotetext{
36 Henri Barbusse, op. cit., p. 33.

37 Ibid., pp. 327-328.

38 Robert Graves, Adiós a todo eso, Barcelona, Edhasa, 2002, p. 182.

39 Erich M. Remarque, op. cit., p. 151.

${ }^{40}$ Henri Barbusse, op. cit., p. 15.

${ }^{41}$ Robert Graves, op. cit., p. 181.

${ }^{42}$ Henri Barbusse, op. cit., p. 28.
} 
peligrosos» ${ }^{43}$, «perros $»^{44} \mathrm{O}$ «bestias que van al frente $»^{45}$ son algunas de las expresiones que utilizan los narradores autodiegéticos para definirse.

De las diferentes identificaciones que pueden establecerse entre el orden humano y el zoológico -situadas en un amplio espectro dependiente de la metáfora estructural «las personas son animales»-, aparecen comúnmente en la literatura bélica las que perfilan en cada persona a un animal salvaje que acostumbra a estar reprimido y que sólo determinados contextos de tensión hacen surgir -la denominación de «bestias» $\mathrm{y}$ «chacales» a los soldados se insertarían en este grupo- y, por otro lado, las que identifican la relación entre los seres humanos con la estructura de dominación del mundo animal -como, por ejemplo, el uso de la palabra «rebaño» para referirse a los grupos de combatientes-.

Otro de los procedimientos para mostrar la degradación que produce la guerra es la comparación entre el carácter ingenuo de los soldados que se ven obligados a participar en ella y el terrible contexto en que se ven inmersos, como se muestra en El fuego. Diario de un pelotón:

No soy malo [...]. Tengo chicos, y en casa me emociona hasta matar a un cerdo que conozca; pero de esos tíos pincharía bien a uno, aunque estuviera metido en un armario ropero. ${ }^{46}$

Que semejante declaración de intenciones sea expresada por una voz narrativa que insiste durante todo su relato en la inocencia de todos aquellos que, independientemente del bando al que representen, se ven obligados a luchar no hace sino reforzar la feroz crítica a la capacidad destructora de la guerra que vertebra toda la novela. El hecho de que el mismo narrador que compadecía a sus oponentes y se identificaba con su sufrimiento -a los que llega a referirse como «ipobres semejantes, pobres desconocidos! ${ }^{47}$ - llegue a desear con tanta saña su muerte demuestra de qué forma la violencia contextual en la que se ve inmerso condiciona sus modos de actuación. Un pasaje de la novela de Remarque evidencia sintomáticamente esta visión aniquiladora del fenómeno bélico. Después de atacar a un enemigo -«apuñalo con furia y siento únicamente cómo ese cuerpo se estremece y cae con todo su peso» ${ }^{48}-$, el

\footnotetext{
${ }^{43}$ Erich M. Remarque, op. cit., p. 108.

${ }^{44}$ Louis-Ferdinand Céline, op. cit., p. 20.

${ }^{45}$ Erich M. Remarque, op. cit., p. 145.

${ }^{46}$ Henri Barbusse, op. cit., p. 39.

${ }^{47}$ Ibid., p. 222.

${ }^{48}$ Erich M. Remarque, op. cit., p. 194.
} 
protagonista y narrador observa la agonía del soldado moribundo y, tras ser consciente de lo sucedido, se dirige a él:

Compañero, no quería matarte. Si volvieras a estar aquí, no lo haría. [...] Ahora me doy cuenta de que tú eres un hombre como yo. He pensado en tus granadas de mano, en tu bayoneta, en todas tus armas... Ahora veo a tu mujer y tu rostro, lo que tenemos en común. ¡Perdóname, compañero! ¿Cómo podías ser mi enemigo? Si tiráramos las armas y los uniformes, podrías ser mi hermano [...] Si salgo de ésta, compañero, lucharé contra todo esto que nos ha destrozado a los dos. A ti, la vida... ¿Y a mí? La vida también. ${ }^{49}$

Tal y como demuestra el pasaje de Sin novedad en el frente, las experiencias de muerte, sufrimiento y deshumanización se convierten en vivencias igualadoras que trascienden cualquier diferencia derivada de la nacionalidad, la raza, la cultura o la situación económica. Por tanto, el sustrato común del dolor es el germen de los sentimientos de hermandad pacifista que transmiten estas novelas. La guerra afecta a todos por igual. Entrar en contacto con sus miserias afecta a todos los que en ella participan, modificando para siempre sus vidas en los niveles físico, psíquico y moral.

Los procesos bélicos contemporáneos se han caracterizado, entre otras cosas, por la puesta en práctica de ofensivas ejecutadas a distancia. Gracias a los avances técnicos, durante todo el siglo XX se perfeccionaron los bombardeos aéreos, los lanzamientos de misiles o el uso de granadas de mano u otros artefactos explosivos. Su utilización se combinó con los tradicionales combates cuerpo a cuerpo, que quedaron relegados a un segundo plano y se reservaron para determinados momentos de la batalla -como el que se expone en la cita anterior-. La proliferación de los nuevos ataques conlleva cierta indiferencia moral en su ejecutor, provocada por la distancia temporal y espacial que en ellos se produce entre víctima y verdugo ${ }^{50}$. Esa indiferencia es análoga al desinterés que la gente acostumbra a tener por todo aquello que suceda fuera de los límites de su comunidad. La atención que, casi de forma innata, muestran los hombres para saber lo que pasa más allá de la experiencia inmediata está condicionada por los criterios de actualidad -escasa distancia temporal- y de proximidad -escasa distancia espacial-. La Teoría de la Información acostumbra, de hecho, a señalar estos dos criterios como requisitos básicos para que un acontecimiento pueda alcanzar el rango de noticia.

\footnotetext{
49 Ibid., p. 201-203.

50 Ernest Jünger reflexionó sobre esta nueva dimensión de las armas de destrucción empleadas a distancia en su obra El Trabajador. Dominio y figura: «Se posee una relación concreta con el ser humano cuando la muerte del amigo Juan o del amigo Pedro provoca un sentimiento más profundo que la noticia de que se han ahogado diez mil personas al desbordarse el río Huang-Ho. La historia del humanismo abstracto comienza, en cambio, con consideraciones como, por ejemplo, la de si matar a un enemigo concreto en París es más inmoral que matar, apretando un botón, a un desconocido mandarín en China» (Ernest Jünger, El Trabajador. Dominio y figura, Barcelona, Tusquets, 1990, p. 276).
} 
La cercanía subraya la condición humana de la víctima, que en los ataques a distancia es vista con cierta abstracción, como si simplemente fuera un elemento de una estadística o un cómputo que reflejase las bajas del enemigo. Asimismo, la implicación emocional que supone ver el rostro del contrario, luchar con él cuerpo a cuerpo u observar sus últimas muecas antes de morir conlleva la preocupación y el sentimiento de culpa a los que se refiere el narrador de la novela de Remarque. Tales sentimientos refuerzan la idea de confusión que los soldados acostumbran a tener durante su estancia en el frente y les llevan a plantearse cuáles son las razones que les han llevado hasta allí y que les impulsan a matar a los miembros del otro bando.

\section{MeMoria y COMPROMiso}

Lo expresado en estas páginas pone de manifiesto cómo en el contexto de la I Guerra Mundial, el compromiso de muchos autores se manifestó a través de una postura contraria a la contienda que incluyó dos actitudes. Por un lado, una condena a la guerra explicitada en la creación literaria basada en la propia experiencia autobiográfica, y en la constatación de que el nivel de horror en las trincheras era bastante más elevado de lo que afirmaban las informaciones que desde el poder se estaban enviado a las sociedades. Por otro, una actitud crítica con todo lo que suponía el conflicto desde la posición de relevancia adquirida en la esfera pública por los escritores, cuyas opiniones, como puso de manifiesto la participación de Émile Zola en el «caso Dreyfuss» de finales del siglo XIX, pasaron a ser referencia para buena parte de la opinión pública. En ambos casos permanecía subyacente la fuerza de dos ideas que, complementarias y necesarias, permitieron la unión de autores de diferentes culturas y nacionalidades -algunas de ellas enfrentadas en la guerra-: el universalismo, que condenaba cualquier exaltación nacional y abogada por la igualdad de todos los pueblos, y el antibelicismo que, consecuentemente, renegaba del enfrentamiento al considerar que la unión de todos los seres humanos hacía ridículo batallar por intereses partidistas. Las dos corrientes ideológicas vertebraron un rechazo a la contienda que, aunque no evitó su desarrollo ni la repetición de un conflicto internacional varios años después, logró constituirse en antecedente de una actitud beligerante y crítica con el poder que con el tiempo se ha erigido en una de las constantes de la intelectualidad.

\section{Bibliografía}

AguAdo, Txetxu, «Imán, La ruta y El blocao: memoria e historia del desastre de Annual», Revista hispánica moderna, 57 (2004), pp. 99-120.

Barbusse, Henri, El fuego. Diario de un pelotón, Madrid, Caro Baroja, 1927.

Blasco IbáÑez, Vicente, Obras completas, Madrid, Aguilar, 1965. 
CASTAÑAR, Fulgencio, El compromiso en la novela de la II República Española, Madrid, Siglo XXI, 1992.

Caudet, Francisco, Las cenizas del Fénix. La cultura española en los años 30, Madrid, Ediciones de la Torre, 1993.

CÉLINE, Louis-Ferdinand, Viaje al fin de la noche, Barcelona, Edhasa, 2007.

Dos PAssos, John, Años inolvidables, Seix Barral, Barcelona, 2006.

FrYe, Northrop, Anatomía de la crítica, Caracas, Monteávila, 1957.

GlaEser, Ernest, Los que teníamos doce años, Madrid, Cenit, 1929.

Graves, Robert, Adiós a todo eso, Barcelona, Edhasa, 2002.

JÜNGER, Ernest, El Trabajador. Dominio y figura, Barcelona, Tusquets, 1990.

MaINER, José Carlos, «Agustín de Foxá: Madrid, de corte a cheka», en Agustín Sánchez Vidal (coord.), Época contemporánea (1914-1939). Primer suplemento. Volumen de Historia y Crítica de literatura española, dirigida por Francisco Rico, Barcelona, Crítica, 1995, pp. 574-577.

-------, La Edad de Plata (1902-1929), Madrid, Crítica, 1975.

Remarque, Erich M., Sin novedad en el frente, Barcelona, Edhasa, 2005.

SARTRE, Jean-Paul, ¿Qué es la literatura?, Barcelona, Losada, 2003.

ZweIG, Stefan, El mundo de ayer. Memorias de un europeo, Barcelona, Acantilado, 2002. 